\title{
Characterization and Optimization of Sorbents Utilized for Emission Control During Coal Gasification
}

\author{
Quarterly Report
}

July 1 - September 30, 1995

Work Performed Under Contract No.: DE-FG21-94MC31426

For

U.S. Department of Energy

Office of Fossil Energy

Morgantown Energy Technology Center

P.O. Box 880

Morgantown, West Virginia 26507-0880

By

Mechanical Engineering/Prairie View A\&M University

College of Engineering and Architecture

P. O. Box 397

Prairie View, Texas 77446-0397

HH

DISTRIBUTION OF THIS DOCUMENT IS UNLIMITED

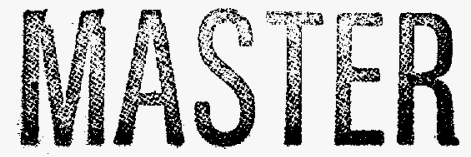




\section{Disclaimer}

This report was prepared as an account of work sponsored by an agency of the United States Government. Neither the United States Government nor any agency thereof, nor any of their employees, makes any warranty, express or implied, or assumes any legal liability or responsibility for the accuracy, completeness, or usefulness of any information, apparatus, product, or process disclosed, or represents that its use would not infringe privately owned rights. Reference herein to any specific commercial product, process, or service by trade name, trademark, manufacturer, or otherwise does not necessarily constitute or imply its endorsement, recommendation, or favoring by the United States Government or any agency thereof. The views and opinions of authors expressed herein do not necessarily state or reflect those of the United States Government or any agency thereof. 


\section{DISCLAMMER}

Portions of this document may be illegible in electronic image products. Images are produced from the best available original document. 
The research activities performed at PV A\&M University in the fourth quarter of 1995 are summarịzed below:

PV A\&MU has decided to use IF\&P filters for its research filter candidates. To further understand IF\&P filter characteristics and the proper research goals, a research discussion meeting was held at IF\&P. On July 17, 1995, Dr. Daniel Mei visited Paul Eggerstedt at IF\&P to discuss research areas on ceramic candle filter performed by IF\&P and the topics interested by IF\&P. IF\&P has performed mechanical and thermal testing on its filters in IF\&P and METC CRADA testing facilities. The characteristics of IF\&P filters are listed below:

- Lightweight filter, low density (17 lbs. per cu. ft.), will reduce stress at candle flange and facilitate tube sheet design and support

- High temperature capability is assured by low thermal expansion at HGCU process temperature

- Fibrosic Candle Filter formed from ceramic oxides, good corrosion resistance at elevated temperature

- High purity chopped aluminosilicate and alumina fibers and binders

- Fibers and binder share similar thermochemical properties, and is free of organic materials

- This characteristics will increase filter resistance to thermal shock and thermal spalling

- Thermal excursions induced crack propagation will also be reduced

- Knitted pore matrix structure

- Microcracks propagation will be blunted and stopped by this structural design

- High pore volume, up to $85 \%$ porosity

The research efforts need to be addressed include the following areas to finalize IF\&P design:

- Back pulse cleaning mechanism for filter clusters

- Cleaning power distribution within candle filter for dust cake removal

- Optimization on back pulse system design

- Steam attack to Fibrosic candle filter design 
- Aluminosilicate and alumina fibers may be vulnerable to high temperature steam attack

On July 20, 1995, Daniel Mei visited Westinghouse STC with METC in-house filter research group, discussing research goals with Tom Lippert and Mary Anne Alvin. For filter life time performance, Mary Anne decided that most filter materials survived 800 degree $\mathrm{C}$ without difficulty, higher process temperature will require better material and structural filter designs. Tom decided that the pressure distributions in filter cluster plenum during back pulse cleanup operation needs more attention. Laboratory research and numerical simulation will help design and optimize filter cleanup design.

From August 15 to August 17, Daniel Mei attended the international conference on hazardous particulate removal. Research specialists were interested in $3 \mathrm{M}$ high temperature ceramic composite filter study. Many questions were raised on the dust cake chemistry, dust cake sintering on candle filters, aerodynamics of dirty gas flow and the cleanup mechanism. Finland and Germany research specialists indicated that the most critical work for dust removal include the understanding of the mechanism for dust agglomeration, dust cohesion and its adhesion to filter surface and the back pulse cleaning mechanism.

PV A\&MU filter research staff shared their research plan with professor $M$. Jhon of Carnegie Mellon University and professor G. Ahmadi of Clarkson University on numerical simulation for back pulse flow and particulate flow pattern per PV A\&MU research setup configuration. PV A\&MU will provide these research institutes with test data for simulation verification in the near future.

Based on the inputs from filter supplier, filter testing institute and other filter research universities, PV A\&MU decided that the understanding of the back pulse cleanup mechanism for filter dust cake removal is a critical and practical research goal. To achieve this research objective, more attention and work were performed at PV A\&MU for filter permeability evaluation and back pulse pressure distribution on IF\&P filters. High temperature testing on filter structure and material strength will be planed in the next quarter accordingly. 
For roor temperature filter study, the work performed is summarized below:

- To better characterize the filter gas flow properties, modifications had been made on the room temperature test facility - a transparent plastic pipe for phase one filter testing and filter characterization. Ten 1/4--20 threaded holes were added on the six (6) inches O.D. by ten (10) foot long transparent pipe. The ten threaded holes were equally spaced along the axis of the filter. This feature will provide more flexibility for pressure flow configuration control, pressure distribution monitoring during inlet gas flow and back pulse cleaning processes. Figure 1 shows the schematic of the previous test setup and Figure 2 shows the modifications done on the setup during this quarter.

- The advanced micro-processor based hand held pressure calibrator and two pressure modules, a 100 psig module and a 250 inches of water differential pressure module, are utilized for pressure transducer calibration and filter permeabilty performance evaluation at room temperature. The hand held pressure calibrator is capable of calculating the flow rate and gas leak rate besides pressure monitoring and measurements. These measured data will help interpret and understand the characterization of IF\&P filter performance.

- Micro-machined silicon sensor cells has been ordered immediately after the installation of IF\&P filters in the filter testing chamber. Pressure transducers ranged from $15 \mathrm{psia}, 30 \mathrm{psig}$ and $150 \mathrm{psig}$ will be installed along the axis of the filter chamber to characterize filter permeability and the pressure distribution within the filter chamber and the filter internal surface.

- A technique has been successfully developed to seal the filter surface. The entire filter test assembly has been pressure tested up to $150 \mathrm{psi}$, and the completely sealed filter was then hermetically pressure tested to $100 \mathrm{psi}$. This sealing technique will facilitate the testing for filter permeability evaluation and back pulse pressure distribution.

- The filter sealing flange assembly had been modified by opening the I.D. of the sealing area, because the filter is not straight and the filter O.D. will be .100 " too big to go through the sealing flange I.D. after the filter is wrapped with sealing material. Because of the size and length constraint of this setup, this modification took about three weeks to complete. 
- Data acquisition system had been ordered to acquire test data automatically. Prior to the arrival of the automatic system, test will be performed semi-manually with the hand held micro-processed unit with less test measurement port.

- A chamber pressure holding assembly had been complete. The pressure sealing diaphragm is capable to seal filter test chamber pressure, and the sealing diaphragm is perforated with special designed device to release chamber pressure per the test plan.

- The permeability distribution of IF\&P filter (unused) has been carefully measured and characterized along the axis of the filters with different exposure percentage of filter surfaces to the gas flow. The tests have been performed with the uncovered filter and covered filter( $50 \%$ and $75 \%$ of the filter length covered from the top). The test results are shown in Figures 3 and 4 . Figure 3 shows the comparison of the leak rate from the test chamber without the filter and with fully uncovered filter. The test result indicates that within the same time elapsed there is no considerable amount of change of leak rate between the test runs(one with filter and the other without filter in place). So the filter is highly permeable i.e. it has negligible resistance against flow. Figure 4 shows the comparison of leak rate from the test chamber between $50 \%$ and $75 \%$ covered filter. The test result shows that the leak rate through $75 \%$ covered filter is less than that of the $50 \%$ covered filter. So the $\%$ of covering along the length of the filter has effect on leak rate. In future more test run will be performed to get more detail about the characteristics of the filters.. Detail filter surface exposure test plan will be based on preliminary filter test results.

- A vacuum system has been designed and acquired. Negative pressure will be supplied to the filter test chamber with the use of the diaphragm sealing technique. The back pulse pressure can be created at various pressure ranges, sealed by the diaphragm per the vacuum pressure level maintained in the filter chamber. Pressure distribution can be measured systematically with this setup. Back pulse inlet configuration can also be designed and optimized with a uniform back pulse flow versus a lance induced jet flow.

- Back pulse intensity can be evaluated with both positive and negative pressure supply outside and inside the filter chamber. The more expensive exterior positive back pressure testing can be optimized based on the vacuumed chamber back pressure testing. 
- The automatic pressure monitoring system is in the initial design phase. This design will help acquire the milli-seconds level pressure monitoring during filter pressure measuring inside and outside the filter within the filter test chamber assembly. All the pressure monitoring devices will be micro-machined silicon pressure sensors, because none of the other sensors are fast enough to catch the pressure distributions within 7 milli-seconds.

\section{Future Plan of Action}

- To study the pressure distribution in a single filter and cluster filters assembly in the filter pressure vessel during gas flow.

- To characterize the permeability of IF\&P filters with pressure and flow conditions as stated in item 1

- To study the back pulse cleaning mechanism as a function of pressure intensity, pulse duration, ject lance design and filter permeability.

- To study the pressure distribution in filter cluster during back pulse cleaning.

- To optimize back pulse design system.

- To optimize tube sheet configuration design.

- To perform numerical simulation on gas flow during gas flow in the pressure chamber.

- To characterize the mechanical and thermal properties of IF\&P filters.

-mechanical and thermal testing.

-micro-structural study(material laboratory analysis). 


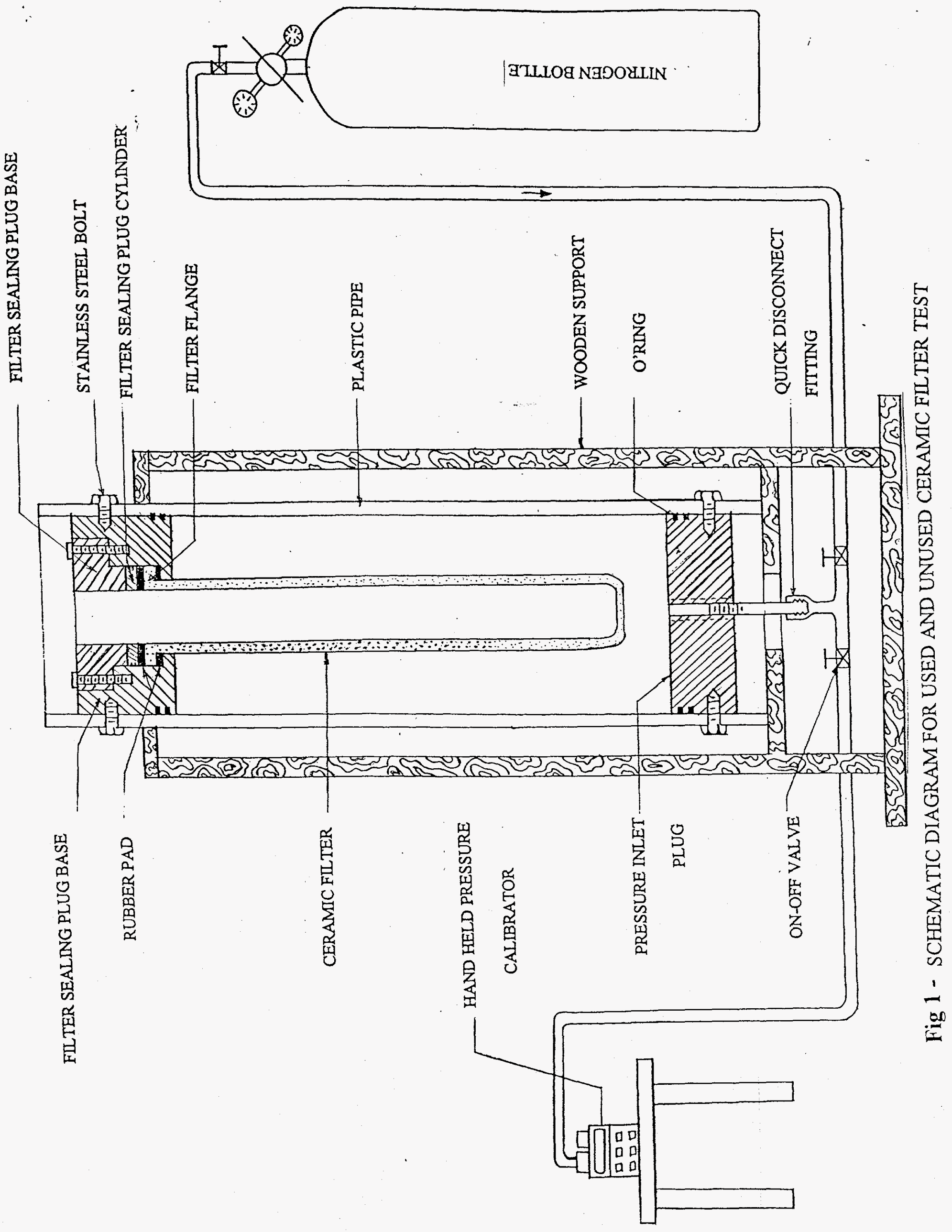




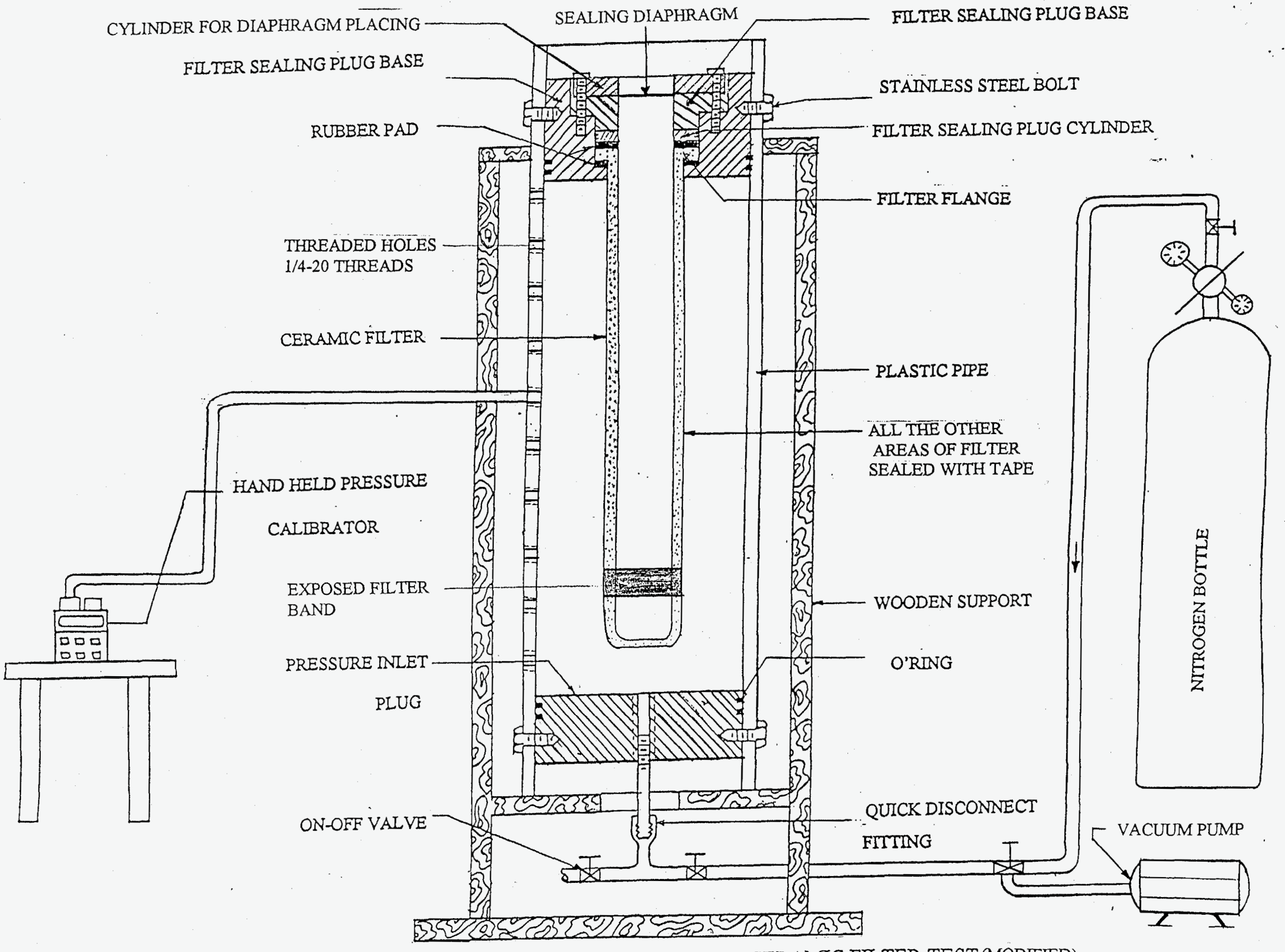

Fig 2 - SCHEMATIC DIAGRAM FOR USED AND UNUSED CERAMTC FILTER TEST (MODIFIED) 
Pressure Drop through Test chamber with and without Filter

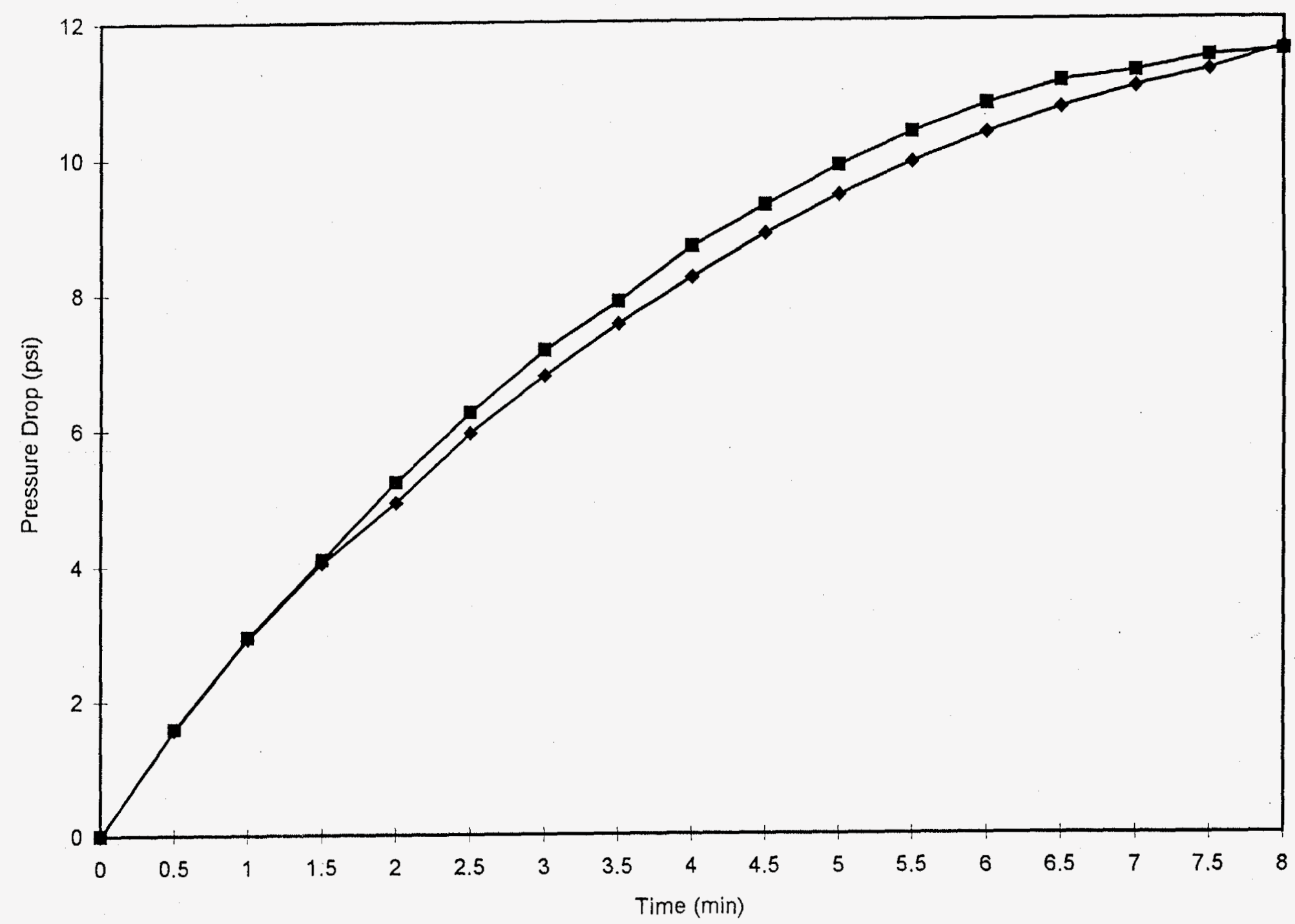

- With filter
$\rightarrow-$ Without filter

Fig 3 